\title{
One-Dimensional Modeling of Transport of Coal Ash in a River-Reservoir System
}

\author{
Mustafa S. Altinakar ${ }^{1, *}$, Nuttita Pophet $^{1}$, Xiaobo Chao ${ }^{1}$ and Reza Marsooli $^{2}$ \\ ${ }^{1}$ National Center for Computational Hydroscience and Engineering, University of Mississippi, \\ Brevard Hall Room 327, University, MS 38677, USA \\ ${ }^{2}$ Dept. of Civil \& Environmental Engineering, Princeton University, E-Quad E316, Princeton, NJ \\ 08544, USA
}

\begin{abstract}
The present study discusses one-dimensional modeling of the coal ash spill into the Dan River in February 2, 2014, using CCHE1D model. The simulations involved unsteady flow hydrodynamics, unsteady non-equilibrium transport of bed material and coal ash in multiple size classes. Discharges of coal ash transport and percentages of coal ash deposited in the mixing layer are presented. The paper presents the investigation of the sensitivity of model results to the rise time and fall time of the triangular hydrographs of pond water and coal ash discharges into the Dan River, the number of size classes used for modeling bed material and coal ash, the mixing layer thicknesses and the nonequilibrium adaptation length.
\end{abstract}

\section{Introduction}

The coal-ash spill incident studied in the present paper occurred on February 2, 2014, at the retired Dan River Steam Station about $6 \mathrm{~km}$ downstream of Eden, North Carolina. The failure of a 48 " corrugated metal pipe under the primary ash pond released 39 short tons (35.4 metric tons) of coal ash and 27 million gallons $\left(102,206 \mathrm{~m}^{3}\right)$ of pond waste water into the Dan River. The leak was discovered by a security official making routine inspection runs on February 2 at 1500 hrs. It is estimated that the bulk of the spill occurred before that time, but the exact timeline is not known. The leak was completely stopped on February 6 at $1500 \mathrm{hrs}$, when the outlet of the failed pipe was completely sealed.

CCHE1D software [1] was used to model the transport and fate of coal ash in the Dan River over a 126.84 mile-long reach using 617 cross sections [2]. The present paper considers only the first 37.64 mile-long (314 cross sections) reach extending from the USGS Wentworth gage to Schoolfield Dam. The cross section data for the reach was obtained by combining the cross section data surveyed by USACE, Engineer Research and Development Center, with the cross section data from FEMA floodplain studies. The discharge hydrograph measured at Wentworth gage (USGS 02071000) was imposed at node 1 . The water discharge hydrograph measured at the stream gage Smith River at Eden (USGS 02074000) was imposed as lateral inflow at rivermile 10.99, which is located at the confluence with the Dan River. The stage-discharge rating curve for the Schoolfield Dam,

\footnotetext{
* Corresponding author: altinakar@ncche.olemiss.edu
} 
based on operational rules provided by the owner, was used as the downstream boundary condition at node 314 .

The suspended load inflow was determined from the sediment rating curves established based on the measurements available at the stream gage Dan River at Paces, VA (USGS 02075500), which is available for the period 1954-1981. The hydrographs of pond water and coal ash released into the Dan River at the spill site were computed based on the measured total release amount and an assumed event timeline. The resulting triangular hydrographs were imposed at node 120 located at the spill site (rivermile 13.81). U.S. Army Corps of Engineers (USACE) Engineer Research and Development Center (ERDC) located in Vicksburg, Mississippi, determined characteristics of the coal ash from a 5gallon sample taken from the breached pond [3]. The bulk density of coal ash ranged from 1.53 to $1.62 \mathrm{gr} / \mathrm{cm}^{3}$. The samples contained about $4-5 \%$ of clay, $50-70 \%$ of silt and $20-40 \%$ sand. The density of coal ash was determined as $\rho_{C A}=2,300 \mathrm{~kg} / \mathrm{m}^{3}$. USACE-ERDC also analyzed bed samples collected at 28 stations between the spill location and the Schoolfield Dam. The particle size characteristics of bed material were determined as $d_{50}=0.279 \mathrm{~mm}$ and $\mathrm{d}_{90}=0.924 \mathrm{~mm}$. The density of the bed material was measured to be $\rho_{s}=2,650 \mathrm{~kg} / \mathrm{m}^{3}$. Based on the grain-size distribution curves measured by the USACE-ERDC, the bed material and coal ash were each represented by 9 size classes in the CCHE1D model as shown in Table 1 [2].

Table 1. Eighteen size classes used to represent bed material and coal ash in the CCHE1D model.

\begin{tabular}{|c|c|c|c|c|c|c|c|c|c|c|c|}
\hline $\begin{array}{c}\text { Size } \\
\text { class } \\
\text { ID }\end{array}$ & $\begin{array}{c}\mathrm{D}_{\text {rep }} \\
(\mathrm{mm})\end{array}$ & $\begin{array}{c}\mathrm{D}_{\text {low }} \\
(\mathrm{mm})\end{array}$ & $\begin{array}{c}\mathrm{D}_{\mathrm{up}} \\
(\mathrm{mm})\end{array}$ & $\begin{array}{l}\text { SG } \\
(-)\end{array}$ & $\%$ & $\begin{array}{c}\text { Size } \\
\text { class } \\
\text { ID }\end{array}$ & $\begin{array}{c}\mathrm{D}_{\text {rep }} \\
(\mathrm{mm})\end{array}$ & $\begin{array}{c}D_{\text {low }} \\
(\mathrm{mm})\end{array}$ & $\begin{array}{c}\mathrm{D}_{\text {up }} \\
(\mathrm{mm})\end{array}$ & $\begin{array}{c}\text { SG } \\
(-)\end{array}$ & $\%$ \\
\hline 1 & 0.0370 & 0.0010 & 0.0370 & 2.65 & 0.00 & 10 & 0.0404 & 0.0356 & 0.0502 & 2.30 & 10.77 \\
\hline 2 & 0.0039 & 0.0000 & 0.0063 & 2.30 & 9.22 & 11 & 0.7070 & 0.5000 & 1.0000 & 2.65 & 24.74 \\
\hline 3 & 0.0480 & 0.0370 & 0.0630 & 2.65 & 0.07 & 12 & 0.0534 & 0.0502 & 0.0633 & 2.30 & 8.65 \\
\hline 4 & 0.0087 & 0.0063 & 0.0126 & 2.30 & 11.05 & 13 & 1.4140 & 1.0000 & 2.0000 & 2.65 & 21.65 \\
\hline 5 & 0.0890 & 0.0630 & 0.1250 & 2.65 & 0.11 & 14 & 0.0713 & 0.0633 & 0.0893 & 2.30 & 13.93 \\
\hline 6 & 0.0162 & 0.0126 & 0.0224 & 2.30 & 11.04 & 15 & 4.0000 & 2.0000 & 8.0000 & 2.65 & 7.54 \\
\hline 7 & 0.1770 & 0.1250 & 0.2500 & 2.65 & 4.10 & 16 & 0.0999 & 0.0893 & 0.1262 & 2.30 & 12.14 \\
\hline 8 & 0.0272 & 0.0224 & 0.0356 & 2.30 & 10.77 & 17 & 8.0000 & 8.0000 & 16.0000 & 2.65 & 0.00 \\
\hline 9 & 0.3540 & 0.2500 & 0.5000 & 2.65 & 41.81 & 18 & 0.1859 & 0.1262 & 0.7096 & 2.30 & 12.41 \\
\hline
\end{tabular}
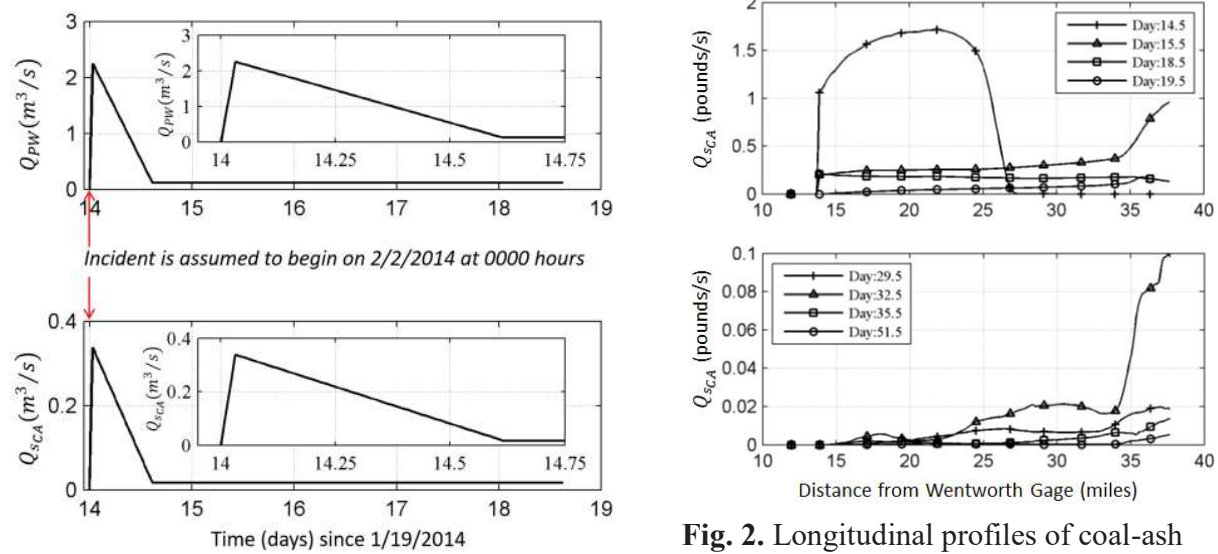

Fig. 2. Longitudinal profiles of coal-ash transport on the days $14.5,15.5,18.5,19.5$, $29.5,32.5,35.5$ and 51.5 . river during the spill event

The original simulations for the project begin on 1/19/2014 at $0000 \mathrm{hrs}$, and continue for 60 days with time step 1 minute. The breach of the pipe occurs on 2/2/2014 at $0000 \mathrm{hrs}$, which is day 14 at 0000 hrs after the beginning of the simulation. Referring to Fig. 1, the release of water and coal ash from the primary ash pond into the Dan River was modeled as a triangular hydrograph that rises to its peak discharge in 1 hour and falls back to a residual 
discharge, which is about $5 \%$ of the peak, in about 15 hours after the initiation of the spill. The residual discharge continues until the breached pipe is finally plugged. This release hydrograph leads to $13 \%$ coal ash concentration by volume in the released mixture. Coal ash concentration by weight in the mixture is $25.71 \%$ and the density of the released mixture is $1,170 \mathrm{~kg} / \mathrm{m}^{3}$. The peak discharges of pond water and coal ash are $2.24 \mathrm{~m}^{3} / \mathrm{s}$ and $0.34 \mathrm{~m}^{3} / \mathrm{s}$, respectively. The release hydrographs were imposed as a lateral discharge at node 120 , which corresponds to the spill location at the rivermile $x=13.81$ miles $(22.22$ $\mathrm{km})$ downstream from the upstream boundary at USGS Wentworth gage. In these simulations, the mixing layer thickness was specified as $\delta_{m}=0.05 \mathrm{~m}$, and the adaptation length was set to $L_{s}=500 \mathrm{~m}$.

\section{Brief description of CCHE1D model}

CCHE1D is a one-dimensional (1D) model that simulates unsteady hydrodynamics, sediment transport, contaminant transport and fate, water quality and fluvial morphodynamics processes in dentritic channel networks [1]. It solves the governing equations of 1D dynamic waves in open-channel flows, i.e. St. Venant equations, and the equations for non-equilibrium sediment transport of non-uniform sediments [4]:

$$
\begin{gathered}
\partial A / \partial t+\partial Q / \partial x=q \\
\partial(Q / A) / \partial t+\partial\left[\left(\beta Q^{2}\right) /\left(2 A^{2}\right)\right] / \partial x+g \partial h / \partial x+g\left(S_{f}-S_{o}\right)=0 \\
\partial\left(A C_{t k}\right) / \partial t+\partial Q_{t k} / \partial x+\left(Q_{t k}-Q_{t^{*} k}\right) / L_{s}=q_{l k} \\
\left(1-p^{\prime}\right)\left[\partial\left(A_{b k}\right) / \partial t\right]=\left(Q_{t k}-Q_{t^{*} k}\right) / L_{s}
\end{gathered}
$$

where $x$ and $t$ are spatial and temporal axes; $A$ is the flow area; $Q$ is the flow discharge; $h$ is the flow depth; $S_{o}$ is the bed slope; $\beta$ is the shape factor for momentum; $g$ is the gravitational acceleration; and $q$ is the lateral discharge per unit channel length. The friction slope is defined as $S_{f}=Q|Q| / K$, where $K$ is the conveyance. In Eq. (3), which is solved for each size class, $C_{t k}$ is the section-averaged sediment concentration of size class $k$; $Q_{t k}$ and $Q_{t^{*} k}$ are the actual and capacity sediment discharges for size class $k$; $L_{s}$ is the nonequilibrium adaptation length; and $q_{l k}$ is the lateral inflow/outflow sediment discharge per unit channel length from banks or tributary streams. Capacity transport discharge for size class $k$ is given by $Q_{t^{*} k}=p_{b k} Q_{t k}^{*}$, where $Q_{t k}^{*}$ is determined using a suitable sediment transport formula, such as Wu et al.'s formula [5] used in the present study. The streambed was modeled in three layers. The topmost layer, of thickness $\delta_{m}$, is the active/mixing layer, which directly interacts with the water column and exchanges sediments. The middle layer is the subsurface layer, which exchanges sediments with the mixing layer. The third and the bottommost layer is the non-erodible substrate layer. CCHE1D tracks all size classes in the water column and the three bed layers; including the bed level changes due to erosion and deposition of each size class, change in the grain size distribution of the bed, and the vertical sorting of sediment sizes. The change in the bed area due to erosion/deposition of size class $k$ is given by Eq. (4), where $p^{\prime}$ is the porosity of the bed material; $\partial\left(A_{b k}\right) / \partial t$ is the bed deformation rate of size class $k$. Detailed information on CCHE1D can be found in $[1]$.

\section{Coal-ash transport simulated with CCHE1D}

Fig. 2 shows longitudinal profiles of the coal-ash discharge at different times after the initiation of the release. On day 14.5 ( 0.5 days after breach) the front of the coal ash has travelled from 13.81 miles to 23.1 miles and the coal-ash discharge is 1.75 pounds/s. On day 15.5 (1.5 after breach), the coal-ash front has reached Schoolfield dam at 37.63 miles $(60.56 \mathrm{~km})$. The transport rates have significantly decreased except immediately upstream 
of Schoolfield Dam. From then on the coal ash discharge are significantly reduced over the entire reach. The day 32.5 (18.5 days after breach), however, displays relatively higher coal-ash discharges, especially immediately upstream of the Schoolfield Dam. During February 19-20, 2014 (5-6 days after breach), a small high-flow event in Dan River, with $Q_{\max }=124 \mathrm{~m}^{3} / \mathrm{s}$, has re-suspended the deposited coal ash and transported it further downstream.

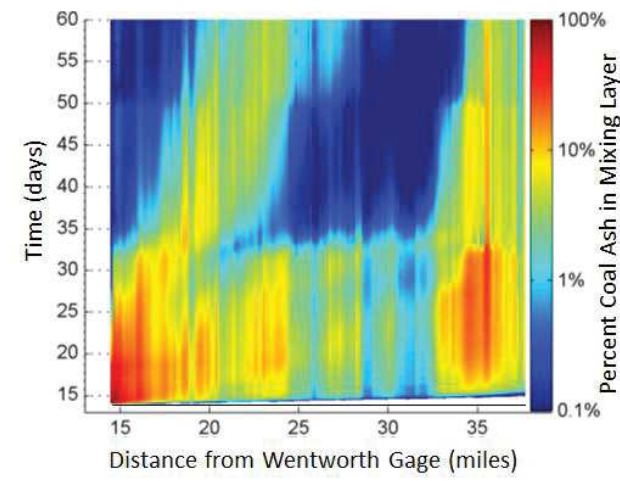

Fig. 3. Space-time representation of percent coal ash in the mixing layer during the first 46 days after breach on 2/2/2014 at $0000 \mathrm{hrs}$.

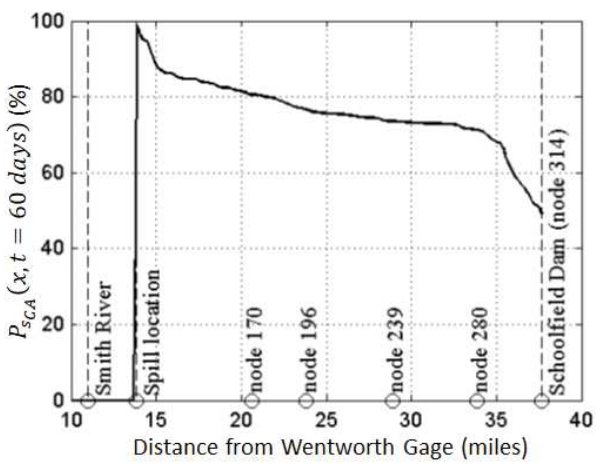

Fig. 4. Longitudinal profile of percentage of the coal ash crossed to down-stream 46 days (day 60) after breach on 2/2/2014 at $0000 \mathrm{hrs}$.

Fig. 3 shows the space-time representation of the percentage of coal ash in the mixing layer for 60 days of simulation (first 46 days after breach). The color bar is scaled logarithmically. Dark red color downstream of the spill location immediately after the spill indicates extremely high percentages (up to $86 \%$ ) of coal ash in the mixing layer. About a day after the spill, the coal ash begins to deposit upstream of the Schoolfield Dam and the percentage of the coal ash in the mixing layers continues to rise. On day 21 ( 7 days after breach), the percentage of coal ash is about $10 \%$ at the Schoolfield Dam. The coal ash in the mixing layer continues to rise and reaches its maximum value of about $23 \%$ on day 37 of the simulation. A second trace of higher coal-ash concentration in the mixing layer starting from the spill location. It represents a slower transport of coarser sizes of coal ash deposited upstream due to subsequent high flow events.

The percent of total released coal ash that passed through the cross section $i$, located at distance $x$ from the spill location, from the beginning of the simulation up to a specific time $t$ is given by:

$$
P_{S_{C A}}\left(x_{i}, t\right)=\frac{M_{S_{C A}}\left(x_{i}, t\right)}{M_{C A}}=\frac{\rho_{C A}}{M_{C A}}\left[\int_{0}^{t} Q_{S_{C A}}\left(x_{i}, \tau\right) d \tau\right]
$$

where $M_{S_{i}}(t)$ is the total mass of coal ash that crosses section $i$ up to time $t$, and $M_{C A}$ is the total amount of coal ash released into the Dan River, which was estimated as 39,000 short tons (35,380 metric tons). The computed profiles of $P_{S_{C A}}(x)$ at selected times $t$ were found to be useful to track the transport and fate of coal ash and to plan cleanup operations.

Fig. 4 shows the profile of percent of total released coal ash passing after 60 days of simulation, i.e. $P_{S_{C A}}(x, t=60$ days $)$. The deposition of coarser sizes downstream of the spill location creates the first break in the slope of the profile at about $x=15$ miles $(24.14$ $\mathrm{km})$. The second break in the profile is observed about $x=35$ miles $(56.62 \mathrm{~km})$ occurs when transported coal ash begins depositing upon entering the reservoir impounded by the Schoolfield Dam. At the downstream end of the reach, about $50 \%$ of the coal ash has passed to the downstream of Schoolfield Dam and 50\% remained upstream. The sudden drop in the profile at about $x=35$ miles $(56.62 \mathrm{~km})$ occurs when transported coal ash 
enters the upstream end of the reservoir impounded by the Schoolfield Dam and begins depositing.

\section{Sensitivity analysis}

\subsection{Sensitivity to the rise time of the release hydrograph}

In the original simulations, the triangular hydrographs of pond water and coal ash release were defined with a rise time (time to peak) of $T_{R}=1 \mathrm{hr}$. Three additional simulations were carried out with rise times of 2, 4 and 6 hours as shown in Fig. 5. For all four hydrographs, the peak pond water and coal ash discharges are $2.24 \mathrm{~m}^{3} / \mathrm{s}$ and $0.34 \mathrm{~m}^{3} / \mathrm{s}$, respectively. In Fig. 6, profiles of $P_{S_{C A}}(x, t)$ computed with four different $T_{R}$-values are plotted at simulation times $t=14$ days $+1 \mathrm{hr}, 14$ days $+6 \mathrm{hrs}, 14.5$ days, 15 days, 16.5 days, 18.5 days, and 60 days. These simulation times correspond to $1 \mathrm{hr}, 6 \mathrm{hrs}, 0.5$ days, 1 day, 2.5 days, 4.5 days, and 46 days after the initiation of breach. On $1 \mathrm{hr}, 6 \mathrm{hr}, 0.5$ days, and 1 day after the breach, the profiles calculated with shorter rise times lead to higher $P_{S_{C A}}(x, t)$ values. The profile computed with $T_{R}=1 \mathrm{hr}$ gives values up to $10 \%$ higher than the profile computed with $T_{R}=6 \mathrm{hrs}$. The differences between $P_{S_{C A}}(x, t)$ profiles computed with different $T_{R}$ become negligible at later times. On 2.5 days, 4.5 days, and 46 days after the initiation of breach, the profiles computed with different $T_{R}$ do not show an appreciable difference.

\subsection{Sensitivity to the fall time of the release hydrograph}

The triangular hydrographs of pond water and coal ash release were defined with a fall time (time to peak) of $T_{F}=15 \mathrm{hrs}$. Two additional simulations were carried out with $T_{F}=$ $10 \mathrm{hrs}$ and $20 \mathrm{hrs}$ as shown in Fig. 7. The rise times were kept as $T_{R}=1 \mathrm{hr}$. For hydrographs with $T_{F}=10,15$ and $20 \mathrm{hrs}$, the peak pond water discharges are 2.76, 2.24 and $1.89 \mathrm{~m}^{3} / \mathrm{s}$ and the peak coal-ash discharges are $0.42,0.34$ and $0.28 \mathrm{~m}^{3} / \mathrm{s}$, respectively.

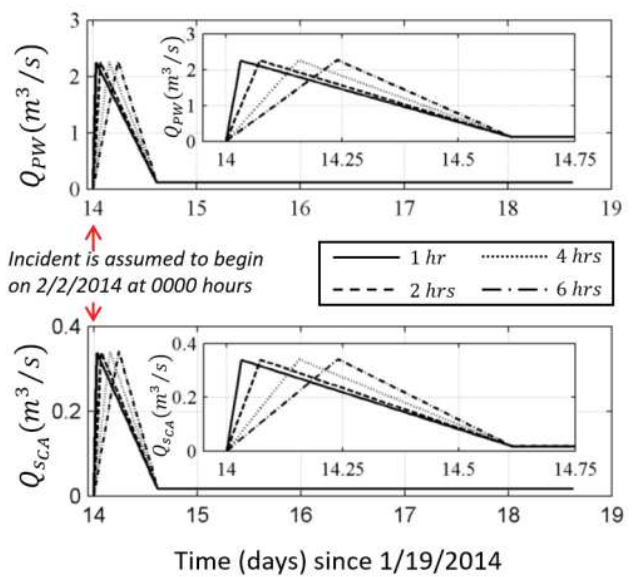

Fig. 5. Triangular coal ash and pond water release hydrographs with different rise times.

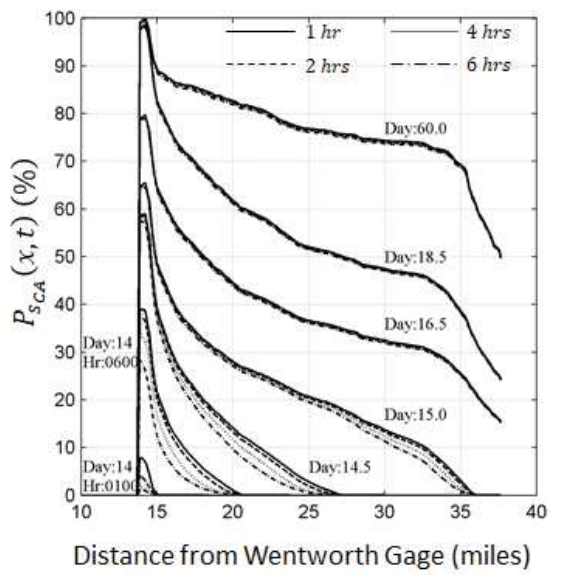

Fig. 6. Profiles of $P_{S_{C A}}(x, t)$ computed with different rise times $\left(T_{R}\right)$.

Profiles of $P_{S_{C A}}(x, t)$ computed with three different $T_{F}$-values are plotted in Fig. 8 at simulation times $t=14$ days $+1 \mathrm{hr}, 14$ days $+6 \mathrm{hrs}, 15$ days, 17 days, and 60 days. These times correspond to $1 \mathrm{hr}, 6 \mathrm{hrs}, 1$ day, 2 days, and 46 days after the initiation of breach. On 
$1 \mathrm{hr}, 6 \mathrm{hrs}, 1$ day, and 2 days after the breach, the profiles calculated with shorter rise times lead to lower $P_{S_{C A}}(x, t)$ values. The profile computed with $T_{F}=10 \mathrm{hr}$ gives values up to $10 \%$ lower than the profile computed with $T_{F}=20 \mathrm{hrs}$. The differences between $P_{S_{C A}}(x, t)$ profiles computed with different $T_{F}$ become negligible later. On day 46 after the initiation of breach, the profiles computed with different $T_{F}$ do not show an appreciable difference.
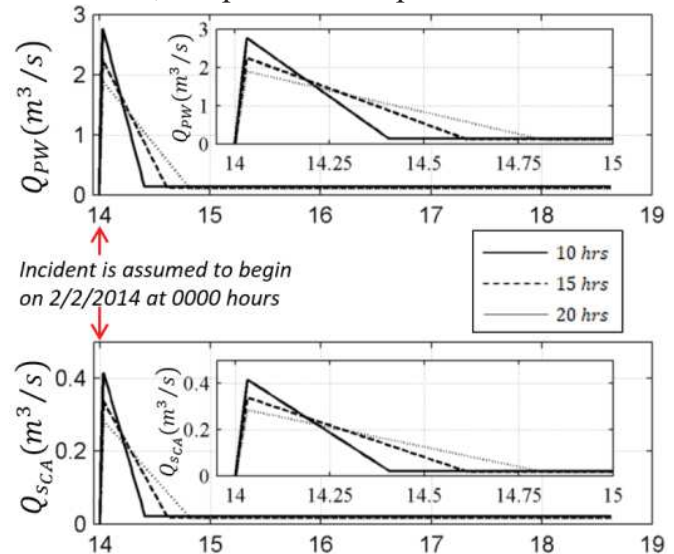

Time (days) since $1 / 19 / 2014$

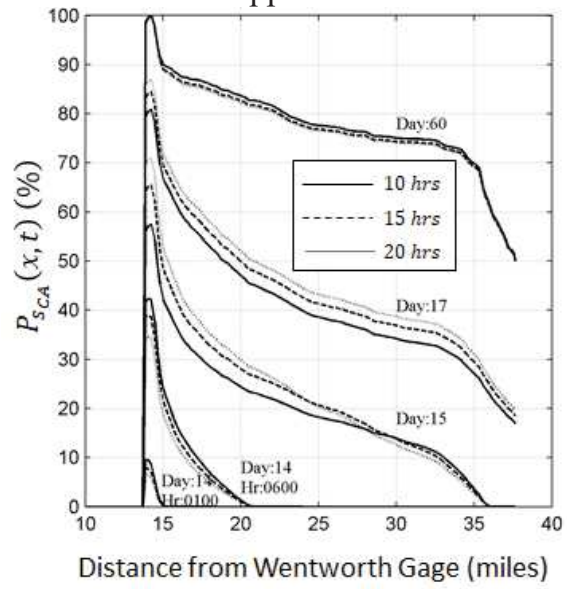

Fig. 7. Triangular coal ash and pond water release hydrographs with different fall times, $T_{F}$.

Fig. 8. Profiles of $P_{S_{C A}}(x, t)$ computed with different fall times $\left(T_{F}\right)$.

\subsection{Sensitivity to number of size classes of bed material and coal ash}

Original simulations were carried out using 9 size classes for bed material (BM) and 9 size classes for the coal ash (CA). To investigate the sensitivity of the simulation results to the number of size classes, the simulations were repeated with 7 and 5 size classes for each. Fig. 9 shows grain size distribution curves for BM and CA approximated with 9, 7, and 5 size classes.

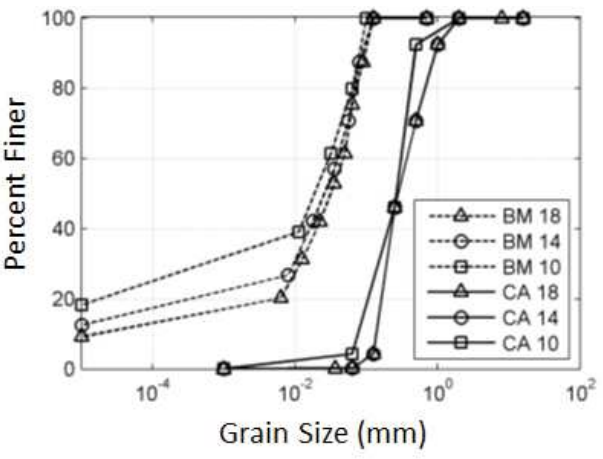

Fig. 9. Bed material (BM) and the coal ash (CA) grain-size distribution curves represented using different number of size classes.

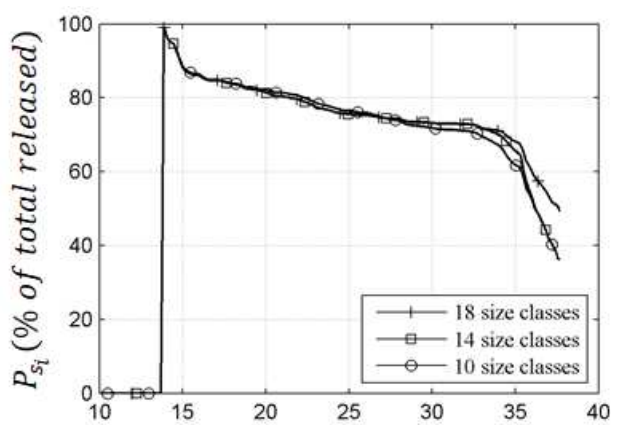

Distance from Wentworth Gage (miles)

Fig. 10. Profiles of $P_{S_{C A}}(x, t)$ computed with different number of size classes.

The profiles of $P_{S_{C A}}(x, t=60$ days $)$ computed using different number of size classes are plotted in Fig. 10 on day 60 (46 days after breach). Results with different size classes give quite similar results for the entire reach, except downstream of rivermile 30 . As expected, the simulation with 18 size classes lead to a higher percentage of coal ash being transported downstream of rivermile 30 and evacuated at Schoolfield Dam. This is because 
the coarser sediments are modeled using higher number of size classes, some of which continue to be transported when the flow enters the reservoir impounded by the Schoolfield Dam.

\subsection{Sensitivity to the mixing layer thickness}

In the original simulations, the mixing layer thickness was specified as $\delta_{m}=0.05 \mathrm{~m}$. Two additional simulations were carried out with $\delta_{m}=0.01 \mathrm{~m}$ and $0.10 \mathrm{~m}$. The profiles of $P_{S_{C A}}(x, t)$ computed using three different $\delta_{m}$-values are plotted in Fig. 11 on day 60 (46 days after breach). It can be seen that, a thinner mixing layer leads to higher transport rates over the entire reach. The $P_{S_{C A}}(x, t=60$ days $)$ computed with $\delta_{m}=0.01 \mathrm{~m}$ is about $5 \%$ higher than that computed with $\delta_{m}=0.10 \mathrm{~m}$. The difference between these two profiles rises to about $10 \%$ immediately upstream of Schoolfield Dam. The differences can be explained by the fact that, in a thinner mixing layer, the percentage of the deposited coal ash is higher. Thus, the coal ash has a higher probability to be entrained into the flow and transported downstream. When the mixing layer thickness is increased, the deposited coal ash mixes with more bed material, and the chance of entrainment into the flow reduces.

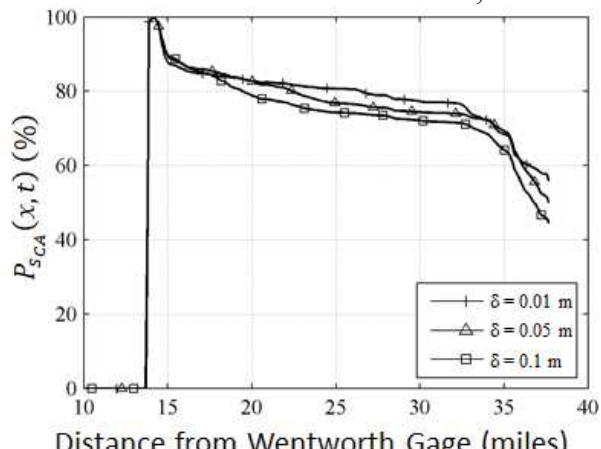

Distance from Wentworth Gage (miles)

Fig. 11. Sensitivity of percent of coal ash crossing downstream after 60 days of simulation to the mixing layer thickness.

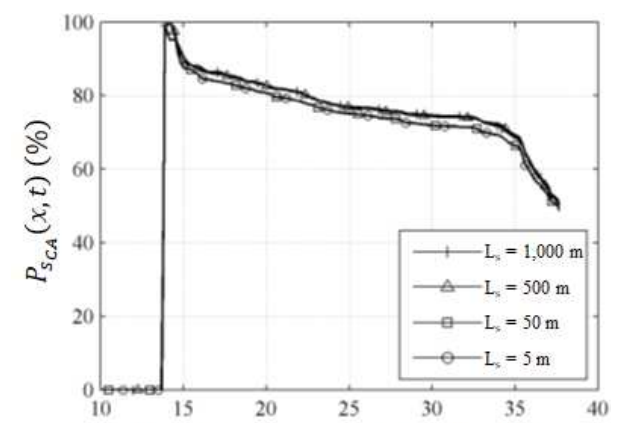

Distance from Wentworth Gage (miles)

Fig. 12. Sensitivity of percent of coal ash crossing downstream after 60 days of simulation to the adaptation length.

\subsection{Sensitivity to the non-equilibrium adaptation length}

The non-equilibrium adaptation length $L_{s}$ in Eq.s (3) and (4) is an important parameter related to the time scale considered $(\mathrm{Wu}, 2008)$. There is no universally accepted value, and the values proposed by different researchers (for example Soni [6], Bell and Sutherland [7], Galappatti and Vreugdenhil [8], Wang [9], Phillips and Sutherland [10], Tran Thuc [11] and $\mathrm{Wu}$ et al. [12]) vary considerably (see also [13]). In the original simulations, the adaptation length was set to $L_{s}=500 \mathrm{~m}$. Three additional simulations were carried out with $L_{s}=5 \mathrm{~m}, 50 \mathrm{~m}$, and $1,000 \mathrm{~m}$. The profiles of $P_{S_{C A}}(x, t)$ computed using four different $L_{s}$-values are plotted in Fig. 12 on day 60 (46 days after breach). It can be seen that even rather large variations in $L_{S}$ does not lead to appreciable differences in $P_{S_{C A}}(x, t=$ 60 days). The profiles for $L_{s}=5 \mathrm{~m}$ and $50 \mathrm{~m}$ are almost the same. Similarly, the profiles for $L_{s}=500 \mathrm{~m}$ and $1,000 \mathrm{~m}$ overlap. The coal ash transport for the simulations with latter two $L_{s}$-values are about $3-4 \%$ higher than the former two $L_{s}$-values. Thus, the coal ash transport and fate simulation results are not sensitive to changes in adaptation length. 


\section{Conclusions}

Failure of a pipe under the primary pond of the Dan River at the Dan River Steam Station in North Carolina on February 2, 2014 led to the release of 39 short tons (35.4 metric tons) of coal ash and 27 million gallons $\left(102,206 \mathrm{~m}^{3}\right)$ of pond waste water into the Dan River. CCHE1D model was used to model the movement of the coal ash over a 126.84 mile-long (204.13 km-long) reach of the river-reservoir system. The simulation results were used for tracking the coal ash through the system and for planning remedial measures. The present study presented the results of the additional simulations to investigate the sensitivity of the simulation results to various modeling choices and parameters, such as rise time and fall time of the triangular coal-ash release hydrograph, number of size classes used to represent coal ash and bed material, mixing layer thickness, and non-equilibrium adaptation length. The findings of the present study can be summarized as follows: (1) Shorter rise times for the triangular hydrograph lead to slightly higher transport rates during the early stages, but two days after the event, the transport rates become the same. (2) Shorter fall times for the triangular hydrograph lead to slightly lower transport rates during the early stages, but two days after the event, the transport rates become the same. (3) Higher number of size fractions lead to slightly higher transport rates in the reservoir impounded by the Schoolfield Dam due to better resolution of coarser size fractions. (4) A thinner mixing layer leads to slightly higher transport rates. (5) Coal ash transport rate is not sensitive to non-equilibrium adaptation length. Unfortunately, it is difficult to generalize, as the results of the sensitivity study depend also on the inflow discharge hydrograph. However, it can be concluded that the results of the simulations are not sensitive to the modeling parameters.

\section{References}

1. Wu, W. and Vieira, D. (2002). Technical Manual of CCHE1D Version 3.0, the University of Mississippi, Oxford, Mississippi.

2. Altinakar, M., Jia, Y., Ding, Y., Chao, X., Zhang, Y., and Ozeren, Y. (2015). Final Report by NCCHE. Submitted to Duke Energy, Charlottesville, NC.

3. Wu, W., Vieira, D., and Wang, S.S.Y., (2004). J. of Hyd. Eng., ASCE, Vol. 130, No. 9.

4. Scott, S. (2014). USACE-ERDC Final Report on "Coal Fly Ash Physical and Erosion Properties and Dan River Thalweg Particle Size Analysis".

5. Wu, W., Wang, S.S.-Y. and Jia, Y. (2000). J. of Hyd. Res., IAHR, Vol. 38, No. 6.

6. Soni, J. P. (1981). Water Resour. Res., 17(1), 33-40.

7. Bell, S.G. and Sutherland, A.J. (1983). J. of Hyd. Eng., ASCE, Vol. 109, No. 3.

8. Galappatti, G., and Vreugdenhil, C. B. (1986). J. Hyd.. Res., 23(4), 359-377.

9. Wang, Z.Y. (1999). J. of Hyd. Res., IAHR, Vol. 37, No. 1.

10. Phillips, B.C. and Sutherland, A.J. (1989). J. of Hyd. Res., IAHR, Vol. 27, No. 1.

11. Tran Thuc (1991). Doctoral Dissertation, Asian Inst. of Technology, Bangkok, Thailand.

12. Wu, W., Rodi, W., and Wenka, T. (2000). J. of Hyd. Eng., ASCE, Vol. 126, No. 1.

13. Wu, W. (2008). Computational River Dynamics. Taylor \& Francis, New York.

\section{Acknowledgments}

The funding received from Duke Energy is gratefully acknowledged. This project was also partially supported by the National Science Foundation under RAPID Grant No. 1438582. 